\title{
A TECNOLOGIA DAS REDES SOCIAIS E A GESTÃO DE PESSOAS NO RECRUTAMENTO E SELEÇÃO DE SEUS COLABORADORES
}

\section{ARTIGO ORIGINAL}

SUMAR, Ramiro Rodrigues ${ }^{1}$

SUMAR, Ramiro Rodrigues. A tecnologia das redes sociais e a gestão de pessoas no recrutamento e seleção de seus colaboradores. Revista Científica Multidisciplinar Núcleo do Conhecimento. Ano 06, Ed. 07, Vol. 12, pp. 74-90. Julho de 2021. ISSN: 2448-0959, Link de acesso: https://www.nucleodoconhecimento.com.br/administracao/colaboradores, $\quad$ DOI: 10.32749/nucleodoconhecimento.com.br/administracao/colaboradores

\section{RESUMO}

Objetivo: Descrever o impacto que as redes sociais podem exercer para o recrutamento e seleção de seus colaboradores. Pergunta Problema: Como a rede social pode favorecer no recrutamento e seleção dos colaboradores de uma empresa? Metodologia: Revisão bibliográfica. Resultados: As evidências dos resultados demonstraram que as tecnologias por meio das redes sociais podem ser relevantes para o recrutamento e seleção de pessoas para a organização. Mas este recrutamento deve ser feito com um olhar diferenciado para cada tipo de rede social pelo recrutador. Considerações Finais: $O$ recrutamento e seleção vêm se modificando como modo tradicional (presencial) para o modo tecnológico (virtual). O estudo mencionou que as redes sociais são ferramentas capazes de trazer para o recrutador candidatos capazes de assumir a organização com responsabilidade e que não existem barreiras no mundo virtual para encontrar o candidato ideal. Ressalta-se a importância de estender este estudo com base em evidências

\footnotetext{
${ }^{1}$ Mestrando em Controladoria, Especialista em Gestão de Tecnologia, Administração estratégica, Segurança da informação e Graduado em Ciências Contábeis.
}

RC: 92499

Disponível

em: https://www.nucleodoconhecimento.com.br/administracao/colaboradores 
científicas, em que pesquisas possam ser realizadas nas empresas para o uso de redes sociais no monitoramento de seus colaboradores.

Palavras-chave: Gestão de pessoas, Redes sociais, Tecnologia da informação e comunicação.

\section{INTRODUÇÃO}

As empresas têm em suas principais metas a obtenção de resultados, todavia, para que isto possa acontecer, o primeiro passo é contratar profissionais capacitados e competentes para fazer parte da equipe. Dentre os departamentos que compõem uma empresa existe a parte de administração dos recursos humanos, que tem como uma de suas funções a de recrutar para a organização seu quadro profissional (CARVALHO, 2015).

A palavra "Administrar" consiste no processo de tomada de decisões e na realização de ações (sejam colaborativas, para melhoria de recursos, de interação, entre outras) para que os objetivos almejados pela empresa possam ser alcançados (COSTA, 2018). Portanto, o foco da Administração de recursos humanos (ou Gestão de pessoas), se relaciona com o desempenho de habilidades, dentre elas: eficiência, eficácia, produtividade, satisfação e comprometimento com as pessoas, sobrevivência da organização, qualidade, competitividade e responsabilidade social (SPADER, 2019).

O gestor precisa ter várias qualidades para poder elencar a sua empresa, dentre estas estão à liderança, a responsabilidade e a empatia para mediar a atuação dos seus colaboradores, para isso precisa saber ouvir e estar aberto para sugestões, ser participativo, e se envolver, principalmente, nas tarefas buscando ser cúmplice na delegação destas (DE BEM NORO; STUKER; DE OLIVEIRA, 2015).

Segundo Ribeiro (2017), o gestor de recursos humanos ou, gestor de pessoas, além de estar capacitado para o cargo, deve possuir ferramentas (avaliação de 
desempenho; feedback contínuo; tecnologias da informação e comunicação entre outras), necessárias para o alcance de uma boa administração, tendo em vista que a parte de recursos humanos é onde serão executados vários processos para que a empresa possa garantir seu nome no mercado empresarial, processos esses que visam recrutar funcionários para completar o sistema organizacional.

Esse recrutamento se dá em diversas formas, a mais utilizada atualmente é por meio das tecnologias. A era tecnológica para as organizações chega com o objetivo de melhorar a qualidade no serviço trazendo rapidez na elaboração de produtos/serviços, fidedignidade nos dados empresariais, maior desempenho pelos colaboradores entre outras qualidades e, garantir mais segurança aos seus usuários. Na gestão de pessoas, as tecnologias favorecem um alcance maior de pessoas a serem recrutadas, além de também auxiliar o gestor no momento de conhecer realmente a vida pessoal de seus colaboradores (SILVA, 2019; PORTO et al., 2016; SANTOS, 2018).

Segundo Motta et al. (2017), a rede mundial de computadores (internet) favorece que as relações entre colaboradores e gestores possam construir novas culturas de relacionamento e saberes, o que pode decorrer a partir dos conhecimentos e das informações provenientes do acesso à internet, com mais intensidade das redes sociais acessadas ou não no ambiente de trabalho.

É primordial ter a compreensão que a gestão de pessoas vem exercendo um papel importante dentro das organizações. Esse papel se modela não se limitando somente a políticas e práticas, mas sim procurando evidenciar nos fatores organizacionais problemas relacionados como: tensões entre os trabalhadores, organização deficiente dentro do ambiente de trabalho, problemas de ordem cultural caracterizando preconceito, para poder controlar o dano causado por um possível assédio moral e que no qual afetará toda a organização da empresa (LEAL; MATOS; FONTANA, 2013).

RC: 92499

Disponível

em: https://www.nucleodoconhecimento.com.br/administracao/colaboradores 
O estudo em questão traz à tona a importância das tecnologias para o recrutamento e seleção dos colaboradores que buscam trabalhar em uma organização. A justificativa deste estudo provém de o pesquisador ter experiência em tecnologias da informação e comunicação e observar que nas redes sociais a oferta de emprego surge com uma demanda bastante significativa, bem como também a observação do modo que a entrevista será realizada (em especial pessoas de nível superior a entrevista se dá pelo google meet). Neste segmento, a pergunta problema desse estudo é: Como a rede social pode favorecer no recrutamento e seleção dos colaboradores de uma empresa?

Portanto, a principal contribuição para a realização deste estudo parte do conhecimento sobre o uso das tecnologias pelos gestores de pessoas, a partir das redes sociais, tornando-o relevante para agregar um maior conhecimento tanto para o profissional como para a sociedade geral. Para a comunidade científica o estudo tem sua relevância agregado a ampliação de conhecimentos sobre o uso das tecnologias para o recrutamento e seleção de pessoas.

O objetivo proposto neste estudo foi descrever o impacto que as redes sociais podem exercer para o recrutamento e seleção de seus colaboradores.

Para que este estudo acontecesse, buscou-se uma fundamentação teórica relacionada aos seguintes temas: $O$ recrutamento e a seleção na empresa; as tecnologias da informação impactando na gestão de pessoas; As redes sociais para o recrutamento e seleção de uma empresa.

Com base nesta fundamentação teórica, o desenho do estudo tem sua metodologia baseada na revisão bibliográfica. 


\section{REFERENCIAL TEÓRICO}

\subsection{A FUNÇÃO DO RECRUTAMENTO E SELEÇÃO NA EMPRESA}

Falando de recrutamento e seleção de pessoas, Oliveira e Bueno (2018) descrevem que este sistema de escolha provém dos homens das cavernas, onde as escolhas das pessoas para desenvolver as atribuições impostas pelo sistema social da época se davam pela sua força, sendo o mais forte condicionado a participar das caças para a alimentação do seu povo. No contexto atual, esta seleção está se tornando cada vez mais difícil.

Chiavenato (2002) menciona a importância do recrutamento e da seleção para a organização. $\mathrm{O}$ autor reforça que ambas as ferramentas de escolha organizacional estão diretamente ligadas ao desenvolvimento da empresa e, que mesmo tendo atribuições diferentes, tem o mesmo objetivo: Identificar o funcionário adequado para compor a organização.

O recrutamento pode ser classificado como interno ou externo. O recrutamento sendo interno acontece quando a organização faz uma modificação no seu quadro de funcionários. Essa modificação decorre do desempenho do trabalhador em seu setor e da necessidade da empresa, o que permite a escolha deste trabalhador que já está sendo observado há algum tempo, a partir da promoção, ou seja, transferindo estes para departamentos ou cargos com maior destaque. A partir desta modificação este funcionário é treinado, para que o seu desempenho possa atingir melhores resultados dentro da empresa com suas atividades (CANALLI; DE ANDRADE, 2016).

Já no recrutamento de forma externa, o colaborador pode ser escolhido através de processos ou por outros meios. Exemplos em relação a estes meios são os anúncios na imprensa, palestras em escolas e universidades, divulgação em associações de classes, por recomendações de terceiros, agências de emprego, arquivos de candidato guardados na empresa que já se apresentaram e intercâmbio

RC: 92499

Disponível

em: https://www.nucleodoconhecimento.com.br/administracao/colaboradores 
de empresas. No recrutamento externo, os anúncios provenientes da empresa e por páginas de divulgação de vagas na internet trazem essa notoriedade de que se precisa de colaboradores (SILVA; FERRETT; MANCINI, 2014).

Portanto, todos os esforços da empresa em trazer para seu círculo novos colaboradores estão relacionados ao recrutamento. Alberton, (2002), descreve que o processo de recrutamento é tido como uma das etapas mais importantes do processo de admissão de um novo profissional. O autor reforça que a maioria das empresas busca em primeiro plano dentro do ambiente interno, para em seguida ir ao mercado de trabalho.

Mozer (2016) reforça que a organização possui culturas diferentes umas das outras. Estas culturas podem fazer com que o trabalho seja realizado de formas diferentes. Todavia, o recrutamento e a seleção não se fazem diferente. O processo pelo qual é realizado o recrutamento da organização tem suas variações, mas os meios utilizados são iguais, podendo ser por intermédio das tecnologias da informação e comunicação, onde são divulgadas as vagas para os cargos dentro da empresa. No caso das seleções, tem-se a decisão pelo qual o candidato se posicionará a partir do melhor desempenho ao cargo que the foi oferecido.

Tanto o recrutamento na forma interna ou externa tem suas vantagens e desvantagens. Para a organização como para os concorrentes ao cargo colocado à disposição na empresa, estas condições devem ser analisadas para identificar a melhor forma de recrutar. As figuras 1 e 2 fazem um demonstrativo destas vantagens e desvantagens do recrutamento interno e externo. 
Figura 1: Vantagens recrutamento interno e externo

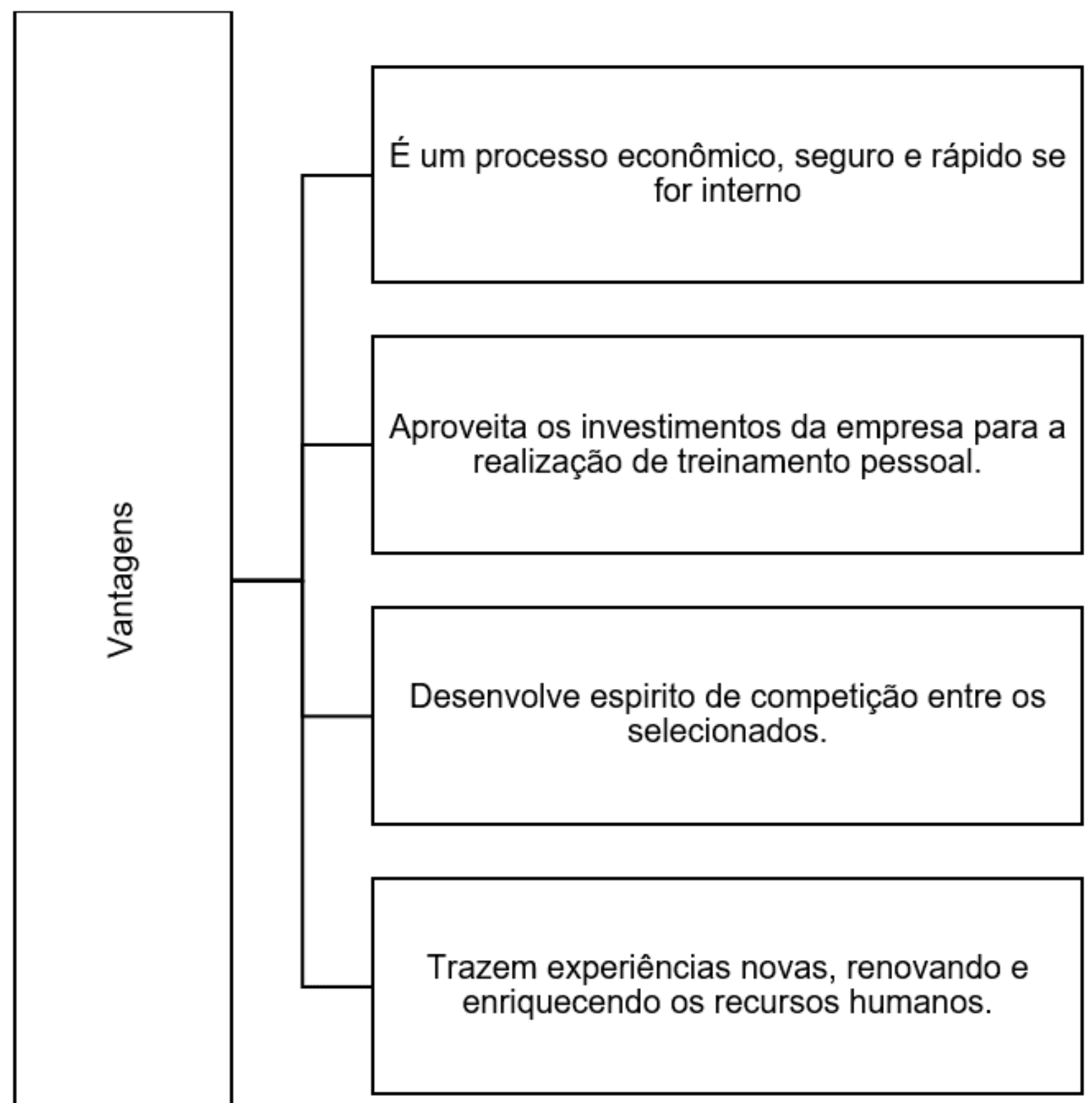

Fonte: Retirado de Chiavenato (2002).

RC: 92499

Disponível 
Figura 2: Desvantagens do recrutamento interno e externo

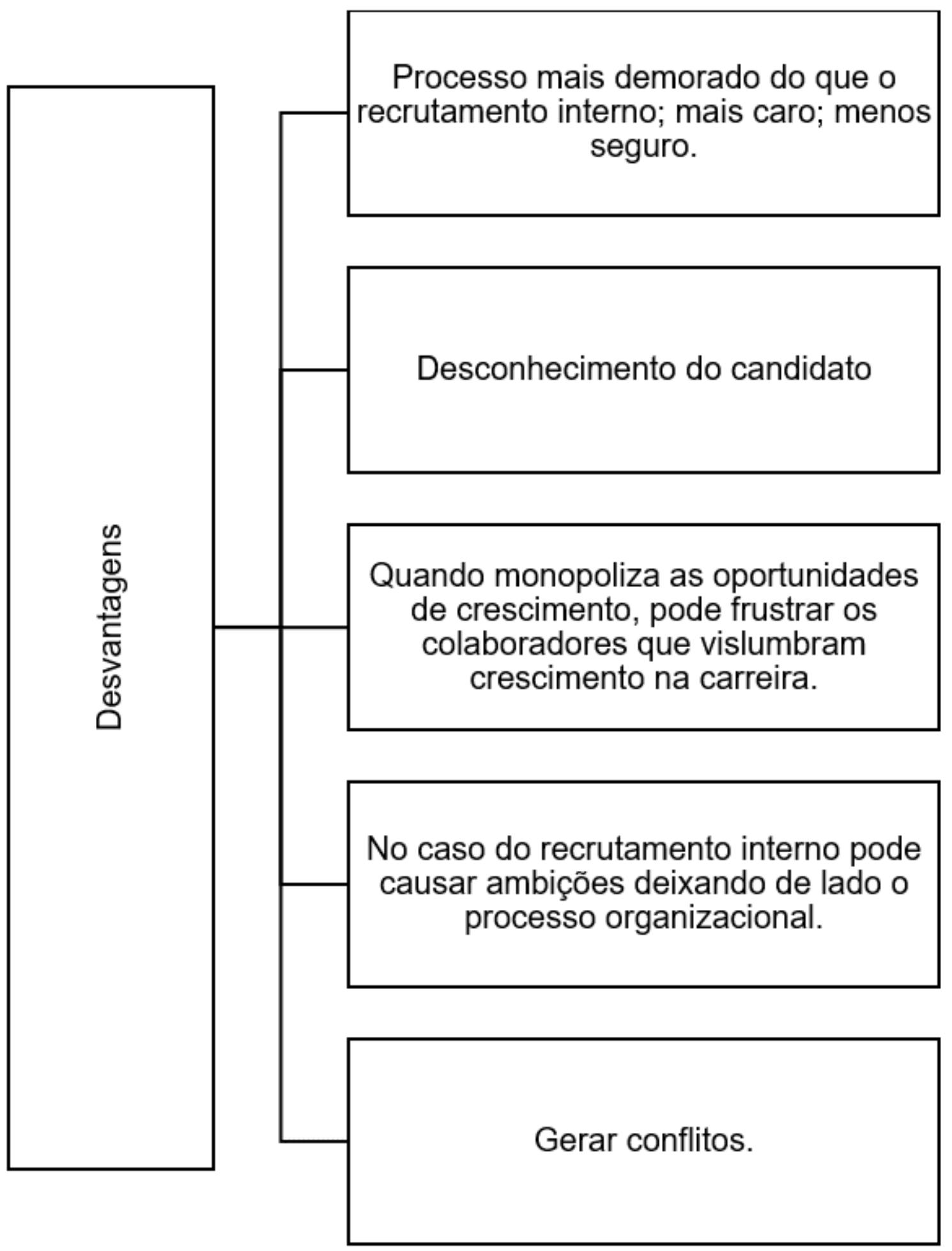

Fonte: Retirado de Chiavenato (2002).

RC: 92499

Disponível

em: https://www.nucleodoconhecimento.com.br/administracao/colaboradores 
Portanto, o recrutamento e a seleção são ferramentas nas quais as empresas estão dispostas a investir, agregando valor aos contratados. Assim, os colaboradores selecionados devem estar aptos para desempenhar a função pela qual concorreu a vaga, e conhecer as políticas que a empresa adota.

Chiavenato (2002) afirma que essas ferramentas podem ser utilizadas paralelamente. A escolha da forma como deverá ser utilizada dependerá da situação, número de candidatos, perfil desejado e, sobretudo, requisitos necessários ao desempenho das funções.

Vale ressaltar que nem todos os ambientes fornecem a condição de formar líderes, esta ação desenvolvida pela gestão de pessoas faz com que o recrutamento interno possibilite por meio da liderança, que o empregado tenha autonomia e tomada de decisão a frente dos demais da equipe, harmonizando assim o ambiente, deixando-o adequado e principalmente capaz de aumentar a rentabilidade e a produtividade dos demais (LEITE, 2019).

\subsection{A OTIMIZAÇÃO NA GESTÃo EM PESSOAS PELA GOVERNANÇA EM TI}

A gestão de pessoas no decorrer dos anos, vem passando por adaptações provenientes de profundas transformações que podem envolver a implementação de ações para a obtenção de resultados. Conforme Wanzerller et al. (2018), a origem do nome gestão vem do latim "gestione", o qual define seu significado como um ato ou efeito de gerir ou gerência e pessoa do latim "persona" que indica um homem ou mulher.

A partir da década de 80 , a globalização tomou conta do cenário econômico, com a evolução das comunicações, desenvolvimento tecnológico e competitividade. Este advento tecnológico conduziu a várias empresas adquirirem novos conhecimentos acerca das tecnologias da informação nas organizações. Portanto, a gestão de pessoas é uma função gerencial que abrange a participação das pessoas dentro das

RC: 92499

Disponível

em: https://www.nucleodoconhecimento.com.br/administracao/colaboradores 
organizações com o objetivo de estas alcançarem as metas e os objetivos organizacionais e individuais almejados (POCHMANN, 2015; STECCA, 2014).

Pessoa et al. (2017, p. 02), descreve que:

É importante hoje em dia que as organizações adotem ferramentas de tecnologia visando resolver suportar o seu negócio. Com o avanço tecnológico, as ferramentas tornaram-se poderosas e até certo ponto cativantes, pela facilidade de uso e integração com vários sistemas. Os profissionais têm necessidade de usar ferramentas que os auxiliem no dia a dia da empresa.

Para que a empresa tenha um bom desenvolvimento é necessário que todos os departamentos estejam alinhados, com um gestor atuante em cada departamento. $\bigcirc$ departamento de gestão de pessoas exerce grande importância para uma organização, pois por meio dele é recrutado e selecionado toda a equipe de trabalho, além de envolver tudo que está ligado à empresa, seja interna ou externamente: ambiente, políticas, sociedade e concorrentes (REIS et al., 2018).

No mundo inteiro, as empresas procuram por meio das ferramentas tecnológicas, um modo de maximizar seus negócios, focando-se no seu desempenho, eficácia, satisfação do cliente, na lucratividade e na eficiência dos serviços. Dentro dos sistemas empresariais podemos perceber que as formas avaliativas estão consolidando o trabalho realizado pela gestão de pessoas, conceito esse amplamente defendido por vários autores conforme fala Lima e Figueiredo (2020) ao elaborar a dissertativa de que somente avaliando o que foi feito no decorrer de um determinado espaço de tempo pode ser identificado a produtividade conseguida nos setores.

Neste sentido, a melhoria da qualidade das organizações nas últimas décadas por meio das tecnologias, vem trazendo benefícios ao mercado empresarial, tais como: otimização dos serviços, melhor desempenho dos colaboradores, competitividade, maximização de resultados entre outros (OLIVEIRA; VASCONCELOS, 2005). Neste contexto, a governança corporativa se tornou a estrutura que visa garantir as 
decisões em relação à organização, garantindo assim os interesses das partes interessadas (BARROS; DA SILVA, GOESE, 2015).

A governança de TI trouxe inovação para a gestão de pessoas. Novato (2014) menciona que a Governança em TI vem sendo classificado por ser um conjunto de elementos que trazem práticas, padrões e relacionamentos estruturados, que são dirigidos por gestores e técnicos em $\mathrm{Tl}$, objetivando a garantia de controles organizacionais, a ampliação do desempenho e dos processos de segurança, minimizando riscos e otimizando a aplicação de recursos, o que traz a $\mathrm{Tl}$ em um alinhamento direcionado para os negócios.

Portanto, as novas tecnologias sugerem transformações não apenas nos processos comerciais, mas também na maneira como os produtos e serviços são criados e comercializados, a estrutura e metas da empresa, a dinâmica da concorrência e a própria natureza do negócio e seus colaboradores (TIDD; BESSANTE, 2015; KON, 2016).

Assim, a governança em TI vem apontando-se como uma ferramenta eficaz e segura na gestão de pessoas para a formatação da estrutura organizacional, envolvendo a definição das pessoas para o alcance do quadro profissional da organização, para que possa ser desenvolvida por esta equipe uma divisão de trabalho harmônica e com responsabilidade objetivando em comum o crescimento da empresa (LORENZETTI et al., 2014).

\subsection{AS REDES SOCIAIS PARA O RECRUTAMENTO E SELEÇÃO DE UMA EMPRESA}

Quando se remete as tecnologias da informação e comunicação para o recrutamento de pessoas, tem-se que, as tecnologias vêm facilitando a vida de muitas organizações, auxiliando na seleção de bons profissionais. As potencialidades das tecnologias, para um bom recrutamento e seleção, vêm cada vez mais sendo utilizadas. Dos Santos; De Oliveira e Centurión (2018) ressaltam

RC: 92499

Disponível

em: https://www.nucleodoconhecimento.com.br/administracao/colaboradores 
que as tecnologias surgem como aliados no recrutamento e seleção de pessoal. Através de meios tecnológicos é possível que as pessoas possam buscar empregos e serem selecionados.

A utilização das redes sociais para a seleção de currículo segundo Lago; Da Silva e Barbosa (2018) está se tornando cada vez mais real, visto que, a partir do uso das redes sociais, existe uma maior abrangência de pessoas para a seleção do cargo oferecido o que permite encontrar o colaborador ideal para o cargo almejado na empresa.

Queiróz e Sanches (2019, p. 472) mencionam que:

Concomitantemente às tecnologias surgiram as redes sociais, onde é possível tomar conhecimento da vida pessoal das pessoas em tempo real; Twitter, Instagram, Facebook, dificilmente se encontra alguém que não possua pelo menos uma dessas redes sociais atualmente. Devido a isso, é comum que em processos seletivos as redes sejam utilizadas para traçar um perfil pessoal do candidato de acordo com suas postagens, sendo critério de exclusão de candidatos.

$\mathrm{Na}$ percepção de Melo (2014), as redes sociais inicialmente eram tidas como instrumentos de encontros e reencontros em uma sociedade pautada pela distância entre as pessoas em razão da globalização. No entanto, os dias atuais permitem que as redes sociais sejam não somente para estes fins, mas alargam suas concepções e evoluem possibilitando o conhecimento e o contato entre pessoas estranhas com grupos específicos de interesse.

Um exemplo do uso das redes sociais é observado no recrutamento online. O recrutamento online é uma ferramenta a qual se diferencia do recrutamento tradicional por ser uma técnica utilizada, associada a tecnologias como a internet. Este tipo de recrutamento tem objetivo de divulgar vagas e selecionar pessoas somente através das redes virtuais (DE LIMA: RABELO, 2018).

Pedroso (2016, p. 25), descreve que: 
O recrutamento online é um método em rápido crescimento, na medida em que, cada vez mais indivíduos disponibilizam os seus Curriculum Vitae (CV) no mercado online por reconhecerem as suas potencialidades. O sucesso deste método está intrinsecamente relacionado com o facto de as empresas conseguirem atingir um maior pool de candidatos com potencial já que as restrições geográficas são menos significativas, ou seja, os indivíduos podem ser abordados por empresas de qualquer parte do mundo como também podem efetuar candidaturas a emprego por qualquer área do globo.

Cassiano; Lima e Zupani (2016) identificam que o modo como acontece a divulgação nas redes sociais para a ocorrência do recrutamento é considerado passivo. Esta forma de recrutamento se dá a partir da divulgação do colaborador nas mídias sociais, uma destas mídias se relaciona ao Facebook e instagram. Outro recrutamento passivo envolve a rede social do Linkedin, nesta rede social o candidato é selecionado pela sua referência de perfil em que consta suas qualificações. Vale salientar que estes recrutamentos são feitos pelas redes sociais e que cada rede social traz uma característica diferenciada sobre o candidato, portanto, cabe ao recrutador saber se direcionar perante a escolha de seus candidatos para a seleção.

De Lima e Rabelo (2018, p. 06) refere que:

\begin{abstract}
O e-recrutamento também pode oferecer constantes informações aos candidatos no que se refere às oportunidades de trabalho advindas de diferentes áreas e organizações. O recrutamento tradicional é frequentemente publicado em anúncios de jornais e revistas que exigem números limitados de caracteres ou informações. Neste sentido, o recrutamento on-line pode ser considerado uma fonte de clareza e ainda uma forma dinâmica, pois pode-se divulgar links que direcionam os candidatos a conteúdos relevantes sobre a organização.
\end{abstract}

Lago; Da Silva Manhães e Barbosa (2018) mencionam na sua pesquisa que as redes sociais e as mídias otimizam o tempo do recrutador e da seleção de pessoas. A utilização de ferramentas tecnológica potencializa a aproximação entre a empresa e o candidato trazendo agilidade na divulgação das vagas e no recebimento de currículos para serem selecionados.

RC: 92499

Disponível

em: https://www.nucleodoconhecimento.com.br/administracao/colaboradores 
Segundo Oliveira (2013, p. 38):

O bom relacionamento interpessoal é um dos fatores que influenciam no satisfatório desempenho das produções diárias de um grupo. Uma equipe que trabalha unida em prol do mesmo objetivo alcança com qualidade e eficiência o que é proposto pelo seu líder.

Neste sentido, se torna imprescindível que o gestor conheça de perto os anseios e objetivos de cada colaborador para a organização. Isto para que não haja desconfortos jurídicos ao identificar algo que não possa trazer benefícios para a organização, ou mesmo ao contrário, o colaborador ser alvo de algo indesejável.

\section{CONSIDERAÇÕES FINAIS}

A pesquisa realizada trouxe à tona um assunto relevante sobre recrutamento e seleção nas organizações dentro das mudanças advindas da tecnologia. A gestão de pessoas é um setor em que se desenvolve todo processo de recursos humanos, neste ambiente, inicia-se a busca pelo colaborador ideal.

Diante das mudanças da globalização, o recrutamento e seleção de pessoas têm sido marcados por novas técnicas de escolha, dentre estas novas técnicas que até então eram presenciais, as redes sociais ganham espaço, derrubando obstáculos geográficos e ampliando a concorrência pela vaga pretendida.

Torna-se evidente que a utilização das tecnologias assume papel relevante na contratação desse colaborador, por meio das redes sociais, potencial ferramenta para o recrutamento e seleção, fazem com que as tecnologias sejam um aliado na tomada de decisões.

Facebook, instagram, Twitter, Linkedin e outras redes sociais vêm sendo notadas por recrutadores com o intuito de encontrar o candidato ideal. Todavia, cada rede social tem sua característica e que o recrutador deve saber como se direcionar a cada rede social buscando o candidato ideal para sua empresa. 
Conclui-se, portanto, que as redes sociais são ferramentas tecnológicas que auxiliam a gestão de pessoas em busca de seus candidatos. Ressalta-se a importância de estender este estudo com base em evidências científicas, em que pesquisas possam ser realizadas dentro de empresas que fazem uso de redes sociais para monitoramento de seus colaboradores.

\section{REFERÊNCIAS}

\section{ALBERTON, Luiz. Uma contribuição para a formação de auditores contábeis}

independentes na perspectiva comportamental. 2002. 270 f. Monografia (Programa de Pós-Graduação em Engenharia de Produção). Universidade Federal de Santa Catarina. 2002.

BARROS, Claudio Marcelo Edwards; DA SILVA, Pedro Ylunga Costa; VOESE, Simone Bernandes. Relação entre o custo da dívida de financiamentos e governança corporativa no Brasil. Journal of Accounting, Management and Governance, v. 18, n. 2, 2015.

CANALLI, Tiago; DE ANDRADE, Érica Fernanda Pereira. Recrutamento interno: uma nova perspectiva sobre plano de carreira. Revista Eletrônica Organizações e Sociedade, 2016, 5.3: 88-100.

CARVALHO, leda Maria Vecchioni. Recrutamento e seleção por competências. Rio de Janeiro: Editora FGV, 2015.

CASSIANO, Cecilia Nascimento; LIMA, Luciana Campos; DOS SANTOS ZUPPANI, Tatiani. A eficiência das redes sociais em processos de recrutamento organizacional. NAVUS-Revista de Gestão e Tecnologia, v. 6, n. 2, p. 52-67, 2016.

CHIAVENATO, Idalberto. Recursos humanos.7 ed. São Paulo: Atlas, 2002. 
COSTA, Esdras da Silva et al. Análise das relações e ações conjuntas entre as empresas do APL têxtil da região metropolitana de São Paulo: contribuições para o seu crescimento. Interações (Campo Grande), v. 19, p. 401-415, 2018.

DE BEM NORO, Greice; STÜKER, Camila; DE OLIVEIRA, João Helvio Righi. A relação das características inerentes aos perfis de liderança no desenvolvimento do processo coaching. Revista Capital Científico-Eletrônica (RCCe) - ISSN 21774153, v. 13, n. 1, p. 59-76, 2015.

DE LIMA, Aryane Santos Henriques; RABELO, Aline Andrade. A importância do erecrutamento e seleção online no processo organizacional. Revista Psicologia,Diversidade e Saúde, v. 7, n. 1, p. 139-148, 2018.

DOS SANTOS, Márcia Gomes; DE OLIVEIRA, Rodrigo Cesar Reis; CENTURIÓN, Wanusa Campos. Recrutamento e seleção estratégicos: processos tradicionais e a influência das mídias sociais. Ideias e Inovação-Lato Sensu, v. 4, n. 3, p. 57, 2018.

KON, Anita. Ecossistemas de inovação: a natureza da inovação em serviços. Revista de Administração, Contabilidade e Economia da Fundace, v. 7, n. 1, 2016.

LAGO, Barbara; DA SILVA MANHÃES, Ana Claudia Tavares; BARBOSA, Marcus Vinicius. O uso de novas tecnologias digitais no recrutamento e seleção de talentos. Revista Interdisciplinar em Gestão, Tecnologia e Saúde, v. 1, n. 01, p. 161-178, 2018.

LEAL, Débora Ribas; MATTOS, Gisele Domingues de; FONTANA, Rosane Teresinha. Trabalhador com deficiência física: fragilidades e agravos autorreferidos. Revista brasileira de enfermagem, v. 66, n. 1, p. 59-66, 2013.

LEITE, André Mourão. O impacto da transformação digital na gestão de pessoas: abordagens estratégicas para atrair, reter e motivar talentos da área de TI na região da grande Florianópolis. Gestão de pessoas-Unisul Virtual, 2019.

RC: 92499

Disponível

em: https://www.nucleodoconhecimento.com.br/administracao/colaboradores 
LIMA, Ricardo Leite; FIGUEIREDO, Giane Lourdes Alves de Souza. Novas estratégias do marketing 4.0 para as organizações. Facit Business and Technology Journal, v. 1, n. 21, 2020.

LORENZETTI, J. et al. Organização do trabalho da enfermagem hospitalar: abordagens na literatura. Texto Contexto Enferm., Florianópolis, v.23, n. 4, p. 110412, out-dez, 2014.

MELO, Cristiane Maria Freitas de. Freedom of expression on social networks: right to criticism of the employee versus image and honor of the employer. 2014. 136 f. Dissertação (Mestrado em Direito) - Pontifícia Universidade Católica de São Paulo, São Paulo, 2014.

MOTTA, Marlton Fontes, et al. O Uso das Redes Sociais no Ambiente de Trabalho e as Estratégias da Gestão de Pessoas para a Gestão de Resultados. In: Congresso de Gestão, Negócios e Tecnologia da Informação-CONGENTI. 2017.

MOZER, André Emílio. Recrutamento e seleção-uma proposta para recrutamento e seleção interno. Gestão em Foco: Revista Eletrônica On Line. Amparo: SP, 2016, 8.1 .

NOVATO, Douglas. 0 que é Governança de TI? OFICINA DA NET. 2014.Disponível em: https://www.oficinadanet.com.br/post/12712-o-que-egovernanca-de- Acesso em: 13/mai/2021

OLIVEIRA, Camila Miles; BUENO, Rose Ângela Vieira Passos. Uma análise da contribuição dos testes psicológicos no processo de recrutamento e seleção de pessoal. Simpósio de Produções Acadêmicas em Psicologia do Univag, n. 1, 2018

OLIVEIRA, Rosane S. O papel do gestor na motivação dos seus colaboradores. Cairu em Revista. Jan 2013, Ano 02, nº 02, p. 33-41, ISSN 22377719. 
PEDROSO, Rita Cipriano. Redes sociais e recrutamento. 2016. 81 f. Tese de Doutorado. Universidade Católica de Portugal. Porto, Portugal, 2016.

PESSOA, Cláudio Roberto Magalhães et al. Da gestão de TI à gestão de informação e tecnologia: uma abordagem teórica da evolução do conceito= From management of technology and information to a management of information and technology: a theoretical approach of concept development. Descobrimentos da Ciência da Informação: desafios da Multi, Inter e Transdisciplinaridade (MIT): XVII Encontro Nacional de Pesquisa em Ciência da Informação (ENANCIB), 2016.

POCHMANN, Márcio. 0 emprego na globalização: a nova divisão internacional do trabalho e os caminhos que o Brasil escolheu. Bomtempo Editorial, 2015.

PORTO, Daniel da Silva et al. Gestão de pessoas: o caso da empresa Yes Contact Center no Município de Florianópolis/SC-Brasil. 2016. Dissertação de Mestrado.

QUEIRÓZ, Monique Mazon; SANCHES, Nathalia Paes. As influências das redes sociais no direito do trabalho. Revista do Tribunal Regional do Trabalho da 15a Região, n. 55, p. 271-280. 2019

REIS, Thompson Augusto, et al. Endomarketing, Liderança e Comunicação: reflexos na organização. Caderno Profissional de Marketing-UNIMEP, 2018, 6.1: 1-17.

RIBEIRO, Antonio de Lima. Gestão de pessoas. Saraiva Educação SA, 2017.

SANTOS, Suênia Soares. Recrutamento e seleção: um estudo do impacto da tecnologia praticado por hotéis da orla de João Pessoa-PB. 2018. $44 \mathrm{f}$. Monografia (Graduação em Hotelaria). Universidade Federal da Paraíba. Paraíba. 2018.

RC: 92499

Disponível

em: https://www.nucleodoconhecimento.com.br/administracao/colaboradores 
SILVA, Bruno de Oliveira Fernandes da, et al. Teoria das Organizações. 2020. $46 \mathrm{f}$. USP - Universidade de São Paulo. Faculdade de Economia, Administração e Contabilidade - FEA-RP. São Paulo. 2020.

SILVA, Jessyca Rodrigues Henrique da. Impactos da tecnologia nos processos de gestão de pessoas: um estudo no setor hoteleiro. 2019. 129f. Dissertação (Mestrado em Turismo) - Centro de Ciências Sociais Aplicadas, Universidade Federal do Rio Grande do Norte, Natal, 2019.

SILVA, Vanessa; FERRETT, Kézia; MANCINI, Ronaldo. Recrutamento e Seleção: Um estudo sobre as técnicas utilizadas nas organizações. ETIC-ENCONTRO DE INICIAÇÃO CIENTÍFICA, 10.10. 2014.

SPADER, Gabriele A influência da competência profissional, da inteligência emocional, da produtividade e do engajamento sobre a satisfação com o trabalho em um ambiente de serviços de saúde. 2019. 93 f. Dissertação (Mestrado em Administração). Universidade de Caxias do Sul. 2019.

STECCA, Jaime Peixoto. Estratégias genéricas na gestão de pessoas e comprometimento organizacional: um estudo em sociedades cooperativas de crédito. 2014. 144 f. Tese. (Doutorado em Administração, Economia e Contabilidade). Universidade de São Paulo. 2014

TIDD, Joe; BESSANT, Joe. Gestão da inovação-5. Bookman Editora, 2015.

WANZERLLER, Rafaela et al. Gestão de pessoas: visão estratégica sobre treinamento e desenvolvimento no contexto das organizações do século XXI. Revista de Administração e Negócios da Amazônia, v. 10, n. 2, p. 67-84, 2018.

Enviado: Maio, 2021.

Aprovado: Julho, 2021. 